\title{
Calmodulin regulates the post-anaphase reposition of centrioles during cy- tokinesis
}

\author{
Yue Yue YU, Gu DAI, Fei Yan PAN, Jie CHEN, Chao Jun LI* \\ Jiangsu Key Laboratory for Molecular \& Medical Biotechnology, School of Life Sciences, Nanjing Normal University. \\ Nanjing 210097, China
}

\begin{abstract}
A transient postanaphase repositioning of the centriole is found to control the completion of cytokinesis. Using a green fluorescent protein-calmodulin fusion protein as a living cell probe, we have previously found that calmodulin is associated with the initiation and progression of cytokinesis. In this study, we further studied the effect of calmodulin on the repositioning of the centriole and subsequent cell cycle progression. When activity of calmodulin is inhibited, the regression of the centriole from the intercellular bridge to the cell center is blocked, and thus the completion of cell division is repressed and two daughter cells are linked by longer cell bridge in perturbed cells. W7 treatment during cytokinesis also results in unfinished cytokinesis and stopped $\mathrm{G}_{1}$ phase. These results suggest that calmodulin activity is required for centriole repositioning and can affect the completion of cytokinesis and cell cycle progression.
\end{abstract}

Keywords: CaM, centriole reposition, cytokinesis, W7.

\section{INTRODUCTION}

Cytokinesis is a very complicated and carefully orchestrated process. During the last step of this process, an intercellular bridge is formed between the two daughter cells. A number of studies suggest that this intercellular bridge is not merely a remnant of the mitotic spindle and cell membrane. In fact, it plays a significant role in cytokinesis completion and the following progression of cell cycle from $\mathrm{G}_{1}$ to $\mathrm{S}$ phase [1]. In addition to microtubules, numerous proteins have recently been identified at the intercellular bridge and they play a role in cytokinesis completion. These proteins include cytoskeleton proteins (actin, intermediate filament proteins), chromosomal passenger proteins (INCENP, TD-60), motor proteins (CENP-E, KLP-3A), protein kinases (Polo and Aurora families), and $\gamma$-tubulin $[2,3]$. Some of the proteins localize at the centriole region during metaphase, redistribute to central spindle, and finally localize to the intercellular bridge.

The $\mathrm{Ca}^{2+} / \mathrm{CaM}$ signal has long been thought to play an important role in cytokinesis due to the observation that

\footnotetext{
"Correspondence: Chao-Jun LI

Tel/Fax: +86-25-83598812;

E-mail: licj@njnu.edu.cn
}

there was a close association between the localized elevation of $\mathrm{Ca}^{2+}$ and the onset of cytokinesis $[4,5]$. Calmodulin (CaM) also relocalizes from the spindle pole during metaphase to the central spindle and intercellular bridge during cytokinesis $[6,7]$. CaM plays a significant role in cytokinesis including furrow formation and regression. The association of CaM with central spindle regulates the initiation of cytokinesis [8]. The injection of either anti-sense mRNA of CaM or CaM-inhibiting peptide always results in failed cytokinesis $[9,10]$. Here we report that CaM is associated with regulation of centriole reposition, a remarkable morphological change that controls the completion of cytokinesis and subsequent transition of the cell cycle from $\mathrm{G}_{1}$ to $\mathrm{S}$ phase. The data gives further evidence that $\mathrm{CaM}$ could regulate the completion of cytokinesis.

\section{MATERIALS AND METHODS}

\section{Cell culture and drug treatment}

Both HeLa cells and $\mathrm{PtK}_{2}$ cells were used in this study. $\mathrm{PtK}_{2}$ cells are more flat than HeLa cells during mitosis and the cell bridge can be more easily observed. Cells were cultured as a monolayer at $37^{\circ} \mathrm{C}$ in MEM supplemented with $10 \%$ fetal calf serum and 100 i.u./ml penicillin and streptomycin.

The cell permeable antagonist of calmodulin, W7 [N(6-Aminohexyl)-5-cholro-1-naphthalenesulfonamide, $\mathrm{HCl}$, 
which inhibits $\mathrm{Ca}^{2+} / \mathrm{CaM}$-dependent phosphodiesterase and myosin light chain kinase (Calbiochem, La Jolla, CA), was added to medium of the synchronized cells. The concentration was calibrated in other experiments by using different concentrations. The maximum inhibitory effect was at $15 \mathrm{mM}$, and was reversible. All the experiments were repeated independently at least 3 times.

\section{Cell synchronization}

Synchronization of $\mathrm{PtK}_{2}$ cells was accomplished by using the double-thymidine block method. Cells were blocked at $\mathrm{S}$ phase and then incubated in fresh medium for $12 \mathrm{~h}$ until cytokinesis before W7 was applied.

To obtain synchronized metaphase HeLa cells, cells cycled to mitosis were blocked by nocodazole (Calbiochem, La Jolla, CA) at a final concentration of 0.2 $\mu \mathrm{g} / \mathrm{ml}$ for $10 \mathrm{~h}$. Synchronized mitotic HeLa cells were then collected and recovered in fresh medium for $100 \mathrm{~min}$ before W7 treatment.

\section{BrdU incorporation}

To compare the BrdU incorporation rate in $\mathrm{W} 7$ treated and untreated HeLa cells, BrdU (Zymed-Lab, South San Francisco, CA) was added directly to the culture medium of the synchronized HeLa cells with a final concentration of $10 \mu \mathrm{M}$. After incubation for $15 \sim 20 \mathrm{~h}$, cells on coverslips were fixed and then immersed in formamide at $100^{\circ} \mathrm{C}$ for $5 \mathrm{~min}$ to denature DNA before staining with anti-BrdU monoclonal antibody.

\section{Immunofluorescence staining}

The immunostaining procedure essentially followed that of Harlow and Lane [10]. For microtubules staining, Triton $\mathrm{X}-100$ was used to permeable cell to get a clear image $(0.2 \%$, added in fixation buffer).

The mouse monoclonal anti- $\beta$-tubulin antibody was purchased from Sera-Lab (Sussex, England), rabbit polyclonal anti- $\gamma$-tubulin antibody from Santa Cruzlab (SantaCruz, CA), and mouse monoclonal anti-BrdU antibody from Zymed-Lab (South San Francisco, CA). TexasRed- or FITC-conjugated goat anti-mouse secondary antibodies and Texas-Red-conjugated goat anti-rabbit secondary antibody were obtained from CalbiochemNovabiochem Corp (La Jolla, CA).

\section{Microscopy}

In all cases, immunostained cells were co-stained for DNA with Hoechst 33342 (Molecular Probes, Eugene, OR). Microscopic observations were made on a Leica DMR microscope equipped with a $100 \times($ N.A. 1.4$)$ objective. Images were captured with a cooled charge-coupled device camera (Dignostic Instruments, MI) and processed using SPOT software (Dignostic Instruments, MI)
A
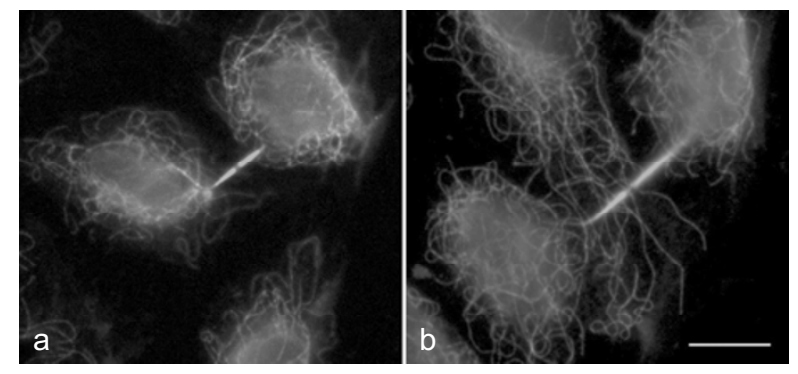

B

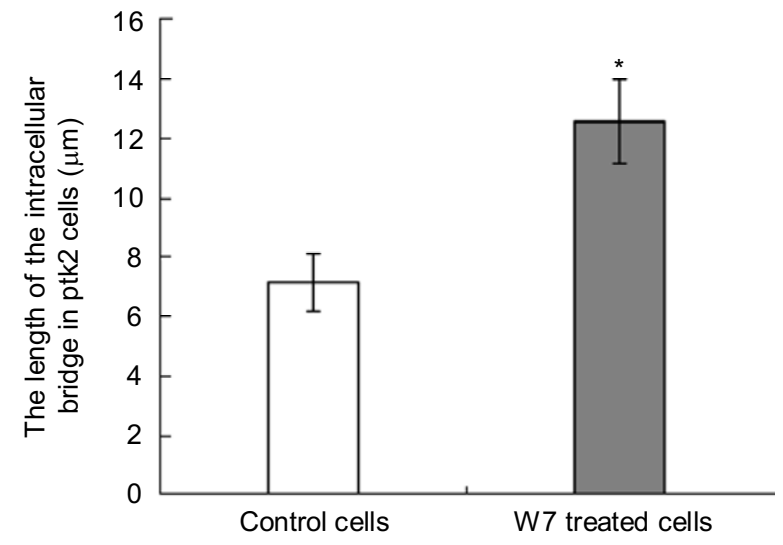

Fig. 1 W7 treatment alters the length of the intercellular bridge. (A) Microtubule immunostaining shows that the intercellular bridge of the W7 treated PtK2 cells is much longer (b) than that of the normal cells (a). Bar $=10 \mu \mathrm{m}$. (B) The average length of the intercellular bridge increased from a mean of $7.14 \pm 0.97 \mu \mathrm{m}(\mathrm{n}=30)$ in the control cells to a mean of $12.56 \pm 1.41 \mu \mathrm{m}(\mathrm{n}=30)$ in the W7 treated cells $\left(^{*}\right.$ : $P<0.01)$.

\section{RESULTS}

\section{CaM affected intercellular bridge abscission}

Successful cytokinesis requires the abscission and eventually resolving of the intercellular bridge connecting the two daughter cells. We have found that CaM concentrates to the cell bridge after cells enter telophase, especially near the "Flemming Body" where cell bridge abscission happens [11]. In order to examine whether the intercellular bridge associated $\mathrm{CaM}$ is also involved in cytokinesis completion, we treated synchronized PtK2 cells with W7 $(15 \mu \mathrm{M})$ for $4 \mathrm{~h}$ at a late stage in cytokinesis when most cells have begun to form intercellular bridges. When the completion of cytokinesis was prolonged by any perturbations, the two daughter cells would be linked by a longer intercellular bridge [12]. As shown in Fig. 1A, W7 treated daughter cells were linked by longer intercellular bridges than those of the untreated cells. The average bridge length increased significantly from $7.14 \mu \mathrm{m}(\mathrm{n}=30)$ in the control cells to $12.56 \mu \mathrm{m}(\mathrm{n}=30)$ in the $\mathrm{W} 7$ treated cells (Fig. 1B, $P<0.01$ ). This suggests $\mathrm{W} 7$ treatment could perturb the abscission of the intercellular bridge and then the exit from cytokinesis. 

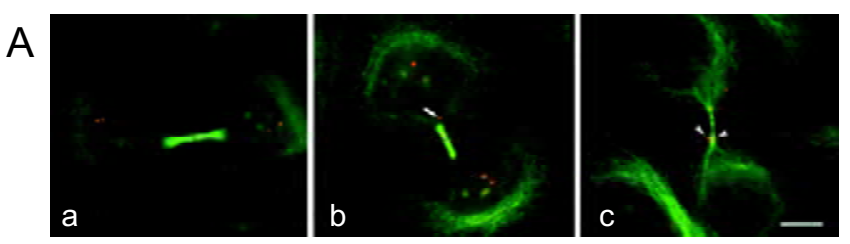

B

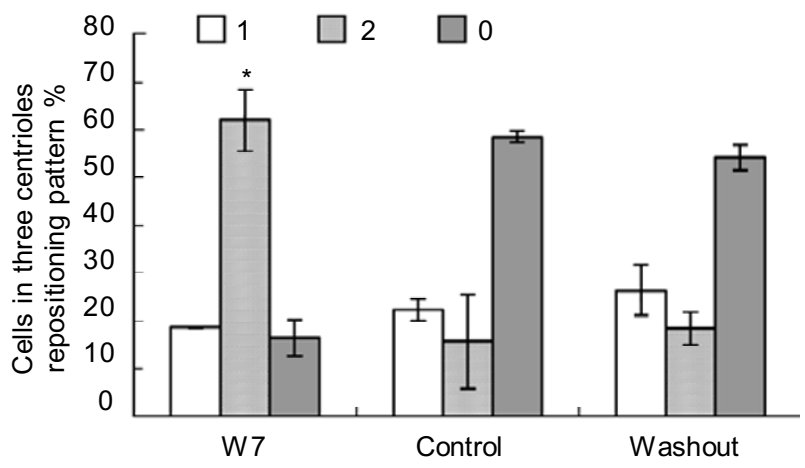

Fig. 2 Three kinds of distribution patterns of the paired centrioles in the intercellular bridge. (A) (a) neither of the paired centrioles in the vicinity of the bridge; (b) one of the paired centrioles (arrow) adjacent to the bridge; (c) both of the paired centrioles (arrowhead) adjacent to the bridge. Bar $=10 \mu \mathrm{m}$. (B) In the $\mathrm{W} 7$ treated group, $63 \%(\mathrm{n}=138)$ of cells have both paired centrioles at the vicinity of the bridge (Fig. 2A c), much higher than the control group (16.75\% $\mathrm{n}=156)$ and washout group $(19.4 \% \mathrm{n}=135)(*: P<0.01)$. The washout group shows similar centrioles repositioning behavior as that of the control group. (The legend: 1 indicates one centriole in the vicinity of the bridge; 2 indicates both of the paired centrioles at the vicinity of the bridge; 0 indicates neither of the centriole in the vicinity of the bridge.)

\section{Centriole reposition was blocked by $\mathrm{W} 7$ treatment dur- ing cytokinesis}

The post-mitotic centriole movement that occurs prior to the completion of cytokinesis has been extensively described by Mack and Rattner [13]. Piel and co-workers further found that the post anaphase repositioning of the centriole controlled the final severing of the intercellular bridge [14]. So we observed the patterns of centriole position after cytokinesis when inhibiting the activity of $\mathrm{CaM}$. We found that the centrioles of most of the control cells would return to the perinucleus region, while the centrioles would retain in the vicinity of intercellular bridge in the perturbed cells, which had longer intercellular bridge and can not enter $\mathrm{G}_{1}$ stage normally. We treated HeLa cells with W7 100 min after synchronization treatment when most cells had formed depressed cleavage furrows. After $2 \mathrm{~h}$ of W7 treatment, cells were either left in W7 (nowashout group), or rinsed with fresh culture medium and recovered for two more hours (washout group). We found that the unresolved intercellular bridges in $\mathrm{W} 7$ treated cells were associated with the blockage of centriole reposition. According to the relative position of the centrioles (as revealed by the two red dots of $\gamma$-tubulin staining in each daughter cell) and intercellular bridge (as revealed by green staining of $\beta$-tubulin), we were able to classify the cells into three centrioles localization patterns: neither of the two centrioles in the vicinity of the bridge (Fig. 2Aa); one of the two centrioles in the vicinity of the bridge (Fig. $2 \mathrm{Ab})$ and both of the two centrioles in the vicinity of the bridge (Fig. 2Ac). We can clearly see that the washout group exhibited similar centrioles repositioning behavior as that of the untreated control cells. On the other hand, a much higher percentage of cells in the no-washout group had both pair of centrioles positioned at the vicinity of the bridge (Fig. 2B, $P<0.01$ ). These results indicate that $\mathrm{W} 7$ may affect the motility of centrioles at the final stage of cytokinesis.

\section{W7 inhibited cytokinesis completion}

To further investigate whether the detained centrioles in the vicinity of the intercellular bridge reflected a signal of a delayed exit from cytokinesis, we checked the progression of cell cycle of HeLa after W7 treatment. It have been indicated that the cells that didn't finish cytokinesis were arrested at $G_{1}$ stage and could not enter $S$ phase

A

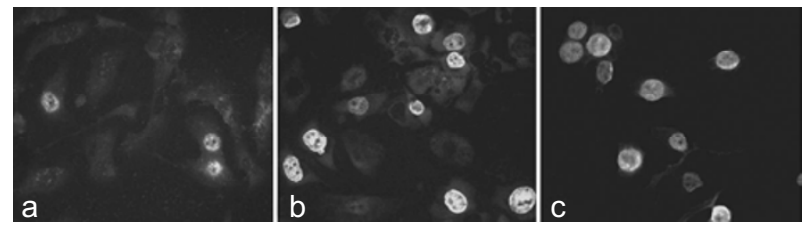

B

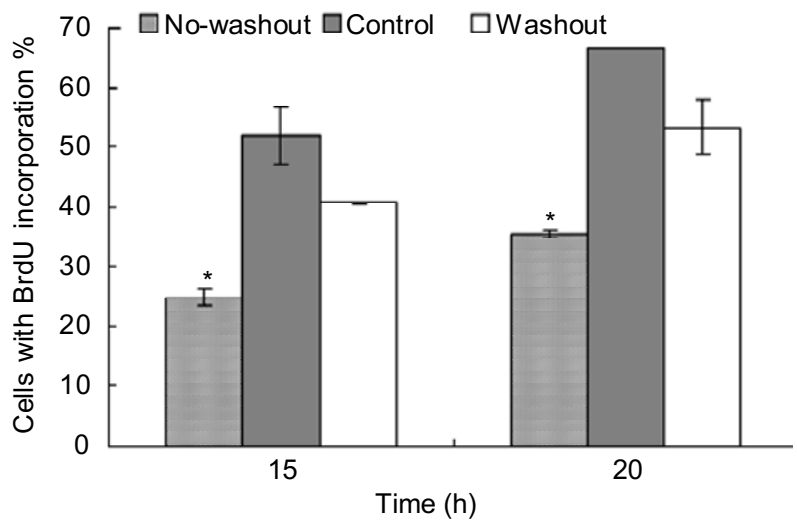

Fig. 3 (A) BrdU incorporation is decreased by W7 treatment after $15 \mathrm{~h}$ treatment. (a: no-washout group, b: washout group, c: control group). (B) The histogram shows the percentage of cells incorporating BrdU in three cell groups at $15 \mathrm{~h}$ and $20 \mathrm{~h}$ after BrdU addition. The W7 treated cells showed a decrease in BrdU staining, and the decrease is more obvious in the no-washout group $(*: P<0.01)$. 
[15]. We found that W7 treated cells (both the washout and no-washout groups) showed a decrease in BrdU staining (Fig. 3A, B). This decrease was particularly notable in the no-washout group $(P<0.01)$. This result confirmed that inhibition of the activity of CaM could block the completion of cytokinesis.

\section{DISCUSSION}

Cytokinesis, the conceptually simple event referring to the separation of the two daughter cells after mitosis, is in fact a precisely regulated process. Several important structures are formed during this process. Our previous study appeared that $\mathrm{CaM}$ might regulate the initiation of cytokinesis by associating with the central spindle [8]. The intercellular bridge is the key structure in controlling cytokinesis completion. Consistent with this view, lots of proteins have been shown to distribute at the intercellular bridge during cytokinesis $[2,3]$. Some of these proteins may serve as structural components of the intercellular bridge, while others may function as signal proteins that mediate the progression of cytokinesis. In our previous study, we have found that $\mathrm{CaM}$ might function during the completion of cytokinesis because it distributed in the middle of the cell bridge near the "Flemming body" where the final abscission happens [11].

Although the intrinsic mechanism is unknown, it has been suggested that the centriole (especially the mother centriole) can 'examine' the spatial organization of the cell, and then determine whether the final cut should occur $[13,14]$. Further studies have demonstrated that the motility of the centrioles is dependent on the microtubulenetwork and regulated by motor proteins, such as dynein and $\mathrm{HsEg} 5[16,17]$. Intriguingly, both dynein and HsEg5 contain CaM binding sites, and CaM can regulate dynein's activity in flagellar motility [18]. The data presented in this report indicate that CaM is required for the successful completion of cytokinesis. When cells were treated with a CaM inhibitor, centrioles retained in the vicinity of the intercellular bridge and the abscission was always deficient. These results are consistent with several other reports that the post-anaphase repositioning of the centrioles controls the exit from cytokinesis [13, 14].

It is apparent that the repositioning of centriole controls the release of central microtubules from the midbody and thus regulates the completion of cell division. $\mathrm{CaM}$ may also directly affect the dynamic stability of the microtubules of the intercellular bridge, since it is well known that $\mathrm{CaM}$ can interact with several MAPs (microtubule associated proteins) such as tau and MAP2 [19-21], and thus indirectly affect the centrioles motility. We hope that the further investigation of CaM's target protein in cytokinesis completion will provide us with more information about this crucial protein and lead us to a better understanding of this complicated processcytokinesis.

\section{ACKNOWLEDGEMENTS}

This work was supported by National Natural Science Foundation of China (Grant No. 30170453) and Foundation of Ministry of Education of China for Distinguished Young Teachers (Grant No. [2001] 39) awarded to ChaoJun LI.

Received, Apr 4, 2005

Revised, June 28, 2005

Accepted, June 29, 2005

\section{REFERENCES}

1 Zeitlin SG, Sullivan KF. Cytokinesis: Breaking up is hard to do. Curr Biol 2001; 11:514-6.

2 Field C, Li R, Oegema K. Cytokinesis in eukaryotes: a mechanistic comparison. Curr Opin Cell Biol 1999; 11:68-80.

3 Glotzer M. The molecular requirements for cytokinesis. Science 2005; 307:1735-9.

4 Meng CL, Chang DC. Study of calcium signaling in cell cleavage using confocal microscopy. Biol Bull 1994; 187:234-5.

5 Chang DC, Meng C. A localized elevation of cytosolic free calcium is associated with cytokinesis in the zebrafish embryo. $\mathrm{J}$ Cell Biol 1995; 131:1539-45.

6 Török K, Wilding M, Groigno L, Patel R, Whitaker M. Imaging the spatial dynamics of calmodulin activation during mitosis. Curr Biol 1998; 8:692-9.

7 Li CJ, Heim R, Lu P, et al. Dynamic redistribution of calmodulin in HeLa Cells during cell division as revealed by a GFP-calmodulin fusion technique. J Cell Sci 1999; 112:1567-77.

$8 \mathrm{Yu}$ YY, Chen Y, Dai G, et al. The association of calmodulin with central spindle regulates the initiation of cytokinesis in HeLa cells. Int J Biochem Cell Biol 2004; 36:1562-72.

9 Liu T, Williams JG, Clarke M. Inducible expression of calmodulin antisense RNA in Dictyostellium cells inhibits the completion of cytokinesis. Mol Biol Cell 1992; 3:1403-13.

10 Harlow E, Lane D. Antibodies, a laboratory manual. Cold Spring Harbor Laboratory Press: New York 1988.

11 Yu YY, Dai G, Chen J, et al. The distribution of calmodulin with midbody and its involvement in cytokinesis regulation. Shi Yan Sheng Wu Xue Bao 2003; 36:335-41

12 Matuliene J, Kuriyama R. Role of the midbody matrix in cytokinesis: RNAi and genetic rescue analysis of the mammalian motor protein CHO1. Mol Biol Cell 2004; 15:3083-94.

13 Mack G, Rattner JB. Centriole repositioning immediately following karyokinesis and prior to cytokinesis. Cell Motil Cytoskel 1993; 26:239-47.

14 Piel M, Nordberg J, Euteneuer U, Bornens M. Centriole-dependent exit of cytokinesis in animal cells. Science 2001; 291:15503.

15 Lanni JS, Jacks T. Characterization of the p53-dependent postmitotic checkpoint following spindle disruption. Mol Cell Biol 1998; 18:1055-64.

16 Robinson JT, Wojcik EJ, Sanders MA, McGrail M, Hays TS. 
Cytoplasmic dynein is required for the nuclear attachment and migration of centrioles during mitosis in Drosophila. J Cell Biol 1999; 146:597-608.

17 Whitehead CM, Rattner JB. Expanding the role of HsEg5 within the mitotic and post-mitotic phases of the cell cycle. J Cell Sci 1998; 111:2551-61.

18 Smith EF. Regulation of flagellar dynein by clacium and a role for an axonemal calmodulin and calmodulin-dependent kinase. Mol Biol Cell 2002; 13:3303-13.

19 Maccioni RB, Cambiazo V. Role of microtubule-associated pro- teins in the control of microtubule assembly. Physiol Rev 1995; 75:835-64.

20 Sánchez C, Díaz-Nido J, Avila J. Phosphorylation of microtubule-associated protein 2 (MAP2) and its relevance for the regulation of the neuronal cytoskeleton function. Prog Neurobiol 2000; 61:133-68.

21 Yamamoto H, Yamauchi E, Taniguchi H, Ono T, Miyamoto E. Phosphorylation of microtubule-associated protein tau by $\mathrm{Ca}^{2+}$ calmodulin-dependent protein kinase II in its tubulin binding sites. Arch Biochem Biophys 2002; 408:255-62. 